\title{
Falta de Garantias e Falhas de Coordenação: evidências do sistema agroindustrial da carne bovina ${ }^{1}$
}

\author{
Silvia Morales de Queiroz Caleman² e Decio Zylbersztajn ${ }^{3}$
}

Resumo: O papel das instituições formais e informais na economia das organizações é tradicionalmente analisado em termos dos mecanismos eficientes de governança que minimizam os custos de transação. Baseada numa perspectiva inversa, a presente pesquisa foca nas falhas de coordenação e no problema da falta de garantias nas transações econômicas. Especificamente, examina-se o conjunto de garantias que suportam a transação entre pecuaristas e a indústria frigorífica em Mato Grosso do Sul com foco nas ineficiências do processo de comercialização de gado para abate. Para a compreensão das falhas de coordenação, propõe-se um constructo teórico baseado em Barzel (1997), que relaciona direitos de propriedade, garantias e instituições. Esse modelo é testado empiricamente por meio do desenvolvimento de duas regressões logísticas múltiplas: i) modelo logit ordenado baseado na percepção de risco dos pecuaristas e ii) modelo probit bivariado recursivo baseado na percepção de risco dos pecuaristas e no papel das ações coletivas. Os resultados apontam para a importância das instituições formais e das ações coletivas como mecanismos geradores de garantias para a transação e, consequentemente, para a minimização dos custos de transação.

Palavras-chaves: falhas de coordenação, garantias, transações complexas, carne bovina.

Abstract: The role of formal and informal institutions in the economy of organizations is traditionally analyzed in terms of efficient governance mechanisms which minimize transaction costs. Based on a different perspective, this paper focuses on coordination failures and the problem of lack of guarantees in sequential transactions. In particular, this research examines a bundle of guarantees which supports the transaction between producers and the meatpacking industry in the Mato Grosso do Sul state regarding the inefficiencies in the trading of ready-to-slaughter animals. A theoretical model based on Barzel (1997)

1 Esta pesquisa é parte de um projeto de um projeto de doutoramento que contou com bolsa de estudos do Conselho Nacional de Desenvolvimento Científico e Tecnológico (CNPq).

2 Professora adjunta no curso de Administração/ Centro de Ciências Sociais da Universidade Federal de Mato Grosso do Sul (UFMS). E-mail: silvia.caleman@ufms.br.

3 Professor titular no curso de Administração da Faculdade de Economia, Administração e Contabilidade (FEA) da Universidade de São Paulo (USP). E-mail: dezylber@usp.br. 
involving property rights, guarantees and institutions is proposed for the understanding of coordination failures. This model is empirically tested with two multiple logistic regressions: i) an ordered logit model based on the producer's risk perception and ii) a recursive bivariate probit model based on producer's risk perception and on the role of collective action. The findings suggest that formal institutions and collective actions play a relevant role in providing guarantees and, thus, representing a source of transaction costs minimization.

Key-words: coordination failures, guarantees, complex transactions, beef.

Classificação JEL: D23.

\section{Introdução}

O sistema agroindustrial (SAG) exportador de carne bovina demonstra crescente participação no mercado internacional, sendo a relevância do setor atestada, igualmente, pela importância da carne bovina como fonte de proteína animal na dieta alimentar dos brasileiros e pela representação da atividade como geradora de renda e emprego em todo o território nacional.

Os ganhos de mercado são acompanhados por mudanças significativas na conduta estratégica das indústrias frigoríficas como abertura de capital, internacionalização e diversificação das atividades. Em paralelo, observa-se, também, um intenso movimento de concentração no setor. Independente dessas mudanças, os conflitos na relação entre produção e indústria frigorífica permanecem, caracterizando uma tradicional rivalidade no setor.

No Brasil, o SAG da carne bovina é caracterizado pela complexidadee diversidade. Ademanda por produtos de qualidade, com rastreabilidade e que atendam a padrões socioambientais somente será atendida por meio de uma adequada coordenação com a produção. Esse novo contexto impõe desafios à coordenação como fator gerador de competitividade. Não obstante a necessidade de coordenação, a dificuldade de coordenação nesse sistema agroindustrial é notória.

Relatos de insucessos de iniciativas de coordenação no SAG da carne bovina são investigados por diversos autores, sendo as falhas de coordenação um problema clássico do setor (EUCLIDES FILHO, 2004;
FERREIRA e BARCELLOS, 2006; JANK, 1996; MALAFAIA et al., 2006; PEROSA, 1999; PIGATTO et al., 1999; ROCHA et al., 2001; SIFFERT FILHO e FAVERET FILHO, 1999; ZYLBERSZTAJN e MACHADO FILHO, 2003; WIAZOVSKI e LIRIO, 2003). A falta de instituições eficientes para dar suporte às transações entre produção e indústria e a alegada dificuldade em estabelecer uma estrutura de incentivos que contemple o necessário alinhamento de preços recebidos e pagos pela indústria estão entre as justificativas apresentadas por Farina e Nunes (2003) para a dificuldade de coordenação desse sistema produtivo. Ainda, a baixa taxa de contratação no SAG da carne bovina no Brasil é apontada por Zylbersztajn (2005) como resultado da dificuldade de coordenação observada nesse SAG.

No final de 2008, a crise econômica global atingiu o setor exportador de carne bovina brasileiro. Diversas indústrias de grande porte do setor entraram em processo de recuperação judicial, não honrando o pagamento aos produtores e, com isso, potencializando o já existente conflito com a classe produtora. O problema torna-se crítico em fevereiro de 2009, quando um dos maiores exportadores nacionais de carne bovina, empresa tradicional e de reconhecida reputação junto a seus fornecedores e clientes, entra com pedido de recuperação judicial. A partir de então, o problema torna-se frequente, com diversas empresas de abate e processamento de carne enfrentando dificuldades financeiras e homologando na justiça os pedidos de recuperação judicial. O resultado é uma massa de credores pecuaristas. 
Atualmente, uma vasta relação de indústrias frigoríficas brasileiras passa pelo processo de recuperação judicial ${ }^{4}$. Independente dos eventos citados existe um histórico de falências fraudulentas de indústrias frigoríficas no setor. Ao se analisar o padrão da transação entre pecuaristas e frigoríficos, fica latente a falta de garantias para o fornecimento de gado para abate, do que decorrem altos custos de transação.

Tendo como contexto o problema apresentado, este artigo é desenvolvido a partir das hipóteses de falhas no delineamento, transferência e garantia dos direitos de propriedade na relação entre produtores rurais e indústria frigorífica de carne bovina, apresentando como questão de pesquisa: i) qual o padrão da transferência de direitos de propriedade na relação produtor-indústria no SAG da carne bovina e ii) qual o papel das instituições formais e informais na solução das disputas?

Objetiva-se estudar a problemática da falta de garantias na transação a partir de seus determinantes e analisar o papel das instituições formais, representadas pelo judiciário, e informais, representadas pelas ações coletivas desenvolvidas por produtores rurais, para a solução dos conflitos no SAG. Para tanto, apresenta-se a ideia de "cadeia de garantias" para a análise do papel das instituições na concessão de garantias para que as trocas econômicas ocorram com baixos custos de transação. A referência teórica é desenvolvida com base nas contribuições de Yoram Barzel (1997) sobre a relação entre direitos de propriedade e custos de transação.

\section{Fundamentação teórica}

A compreensão da natureza do conflito no processo de troca econômica é desenvolvida neste artigo sob o argumento das falhas das instituições em garantir os direitos de propriedade. Para tanto, consideram-se as contribuições de Yoram

4 Entre os casos recentes de indústrias frigoríficas em recuperação judicial estão: Quatro Marcos, IFC, Margen, Arantes, Frigoestrela, Independência, Frialto e Frigol.
Barzel que associa a concessão de garantias com os custos de transação. Para o autor, custos de transação são definidos como os recursos utilizados para estabelecer e manter direitos de propriedade, incluindo os custos envolvidos com a proteção e captura de tais direitos. Com base em Willianson (1985), as contribuições de Barzel devem ser analisadas tanto sob o enfoque da eficiência dos incentivos gerados por um ambiente institucional forte (direitos de propriedade claros e bem delineados) quanto sob a lógica dos custos de transação em que os aspectos de mensuração são preponderantes.

Para North (1991), as instituições têm por objetivo estabelecer e proteger direitos, sendo estas entendidas como as regras do jogo de uma sociedade, estabelecendo limites às interações humanas tanto por meio de regras formais (leis, direitos de propriedade, regulamentações) quanto informais (tradições, tabus e costumes). Por outro lado, as instituições representam incentivos às relações humanas com o papel de organizar o ambiente de negócio, reduzir as incertezas e, junto a outros instrumentos econômicos, definir um conjunto possível de escolhas, criando um ambiente favorável para o processo de tomada de decisão.

Para Demsetz (1967), falhas na proteção dos direitos de propriedade abrem espaço para a existência de externalidades. Para o autor, direitos de propriedade claros e bem delineados geram incentivos para a "internalização" das externalidades. Estando a existência de externalidades associada à ocorrência de falhas, fica claro o papel das instituições para maior eficiência do processo de troca econômica. Ainda sob enfoque da importância da proteção e garantia dos direitos de propriedade, Barzel (1997) avança ao propor que os direitos de propriedade podem ser legais e/ou econômicos e discute as implicações de sua proposição.

A distinção entre o direito de propriedade legal e o direito econômico é feita com base na identificação de a quem compete garanti-los. Ao Estado é atribuída a responsabilidade de garantir os direitos definidos pela lei, chamados 
direitos legais, e à firma e outros arranjos institucionais competem os direitos econômicos. Considerando-se a troca de bens ou serviços, o valor do direito econômico é o valor do bem disponível descontados os custos de proteção e captura. A questão central é que a definição e a garantia dos direitos têm um custo; logo, os direitos não são perfeitamente delineados.

Partindo da premissa de que a garantia perfeita dos direitos de propriedade não é possível senão a custos proibitivos, a delimitação perfeita dos direitos é falha. Com isso, custos de transação são sempre positivos, e em toda transação algum valor está em domínio público.

De acordo com Barzel (1997), os direitos em domínio público são passíveis de captura e os agentes investem na apropriação desse valor. A oportunidade de captura ocorre quando parte dos direitos está em domínio público, não sendo garantidos pelo Estado e economicamente ainda não protegidos de forma eficiente por um agente. Sob esse ponto de vista, os indivíduos maximizam suas utilidades ao maximizar seus direitos. Esse argumento confere uma complexidade maior ao conceito de utilidade comumente tratado pela teoria neoclássica.

Do conflito pela busca de captura e proteção dos direitos aferidos na transação decorre uma dissipação de valor. Entendendo-se a dissipação de valor como perda de eficiência, poder-se-ia afirmar que do processo de disputa por proteção e captura de direitos pode-se criar um ambiente favorável para a ocorrência das falhas organizacionais e possível exercício de poder de mercado.

Os aspectos informacionais e, especificamente, o custo de mensuração dos atributos transacionados são determinantes para a alocação eficiente dos direitos de propriedade. De acordo com Barzel (1997), a dificuldade na definição dos direitos está relacionada ao caráter multidimensional e à variabilidade do atributo, abrindo-se, assim, espaço para a captura de valor. $\mathrm{O}$ autor defende que entender a variabilidade do ativo e identificar as garantias oferecidas é relevante para a análise da forma organizacional mais eficiente para governar a transação. Ciente de que a eficiência está relacionada à minimização da dissipação de valor, as garantias assumem papel preponderante para fazer face à variabilidade e, assim, garantir eficiência no processo de troca.

Na ausência de variabilidade ou em situações em que os atributos são mensuráveis a baixo custo não há necessidade de se prover garantias à transação e o mercado é a forma de governança mais eficiente para a transação. A presença de custos de transação, sob a ótica de Barzel, está relacionada à presença da variabilidade dos ativos. Assim, o problema econômico está na alocação da variabilidade e nas garantias oferecidas para a minimização do seu impacto na geração do valor.

Com isso, as formas de garantia oferecidas à transação estão relacionadas ao tipo de arranjo institucional adotado. Se a garantia é dada pelo poder coercitivo do Estado, têm-se os contratos formais e o mercado como forma organizacional mais eficiente; se a garantia tem como base a reputação, surgem os contratos relacionais como arranjos institucionais híbridos para a governança da transação. Finalmente, quando a garantia à variabilidade do produto é oferecida pelo capital patrimonial da firma, tem-se como solução a internalização da transação na firma (BARZEL, 2002). Sob essa lógica torna-se fácil compreender a concepção de firma como um conjunto de garantias, conforme apregoado por Barzel (1997).

Do mesmo modo que as firmas surgem para resolver o problema de garantia para a variabilidade do ativo transacionado, os arranjos institucionais híbridos (contratos relacionais) também demandam soluções de garantia para que a transação ocorra de modo eficiente. Uma alternativa ao problema da variabilidade e da consequente necessidade de garantias é o investimento em reputação e a construção de marcas. Ambos são mecanismos voltados para a redução dos custos de mensuração da variabilidade.

Em síntese, em se tratando de transações que impliquem a troca de direitos legais, as 
instituições formais (Judiciário) proveem as garantias necessárias para a proteção do valor transacionado. Considerando-se, porém, um ambiente institucional frágil e pouco eficiente na proteção dos direitos ou atributos cujo valor é de difícil mensuração, surge a necessidade de capital patrimonial (firma) e/ou capital reputacional (contratos relacionais) como formas de prover garantias às transações.

Deste modo, a eficiência da transação está relacionada ao tipo de arranjo institucional adotado pelos agentes e às garantias oferecidas para a redução da dissipação do valor.

\subsection{Cadeia de garantias}

Com base na fundamentação teórica apresentada, poder-se-ia afirmar que para se analisar a eficiência/ineficiência das transações é fundamental o estudo da sua "cadeia de garantias". Em situações em que os atributos transacionados são de fácil mensuração ou de baixo custo de mensuração, as instituições formais proveem as garantias necessárias, sendo estas representadas pelo poder coercitivo do Estado. Nesse caso, as transações ocorrem no mercado por meio de contratos. Em situações em que os atributos transacionados são de difícil mensuração (ou alto custo de mensuração), as garantias são baseadas na reputação/confiança (capital reputacional), nos seguros oferecidos por terceiras partes (capital de terceiros) e no patrimônio da firma (capital patrimonial).

De acordo com Barzel (1982, 1997), a eficiência da transação depende da alocação da variabilidade. Para tanto, o agente responsável pela variabilidade do atributo deve prover as garantias necessárias para que a transação ocorra a baixo custo de transação. Assim, a ocorrência de falhas no processo de troca decorreria da

Figura 1. A Cadeia de Garantias: arranjos institucionais e fontes de garantias.

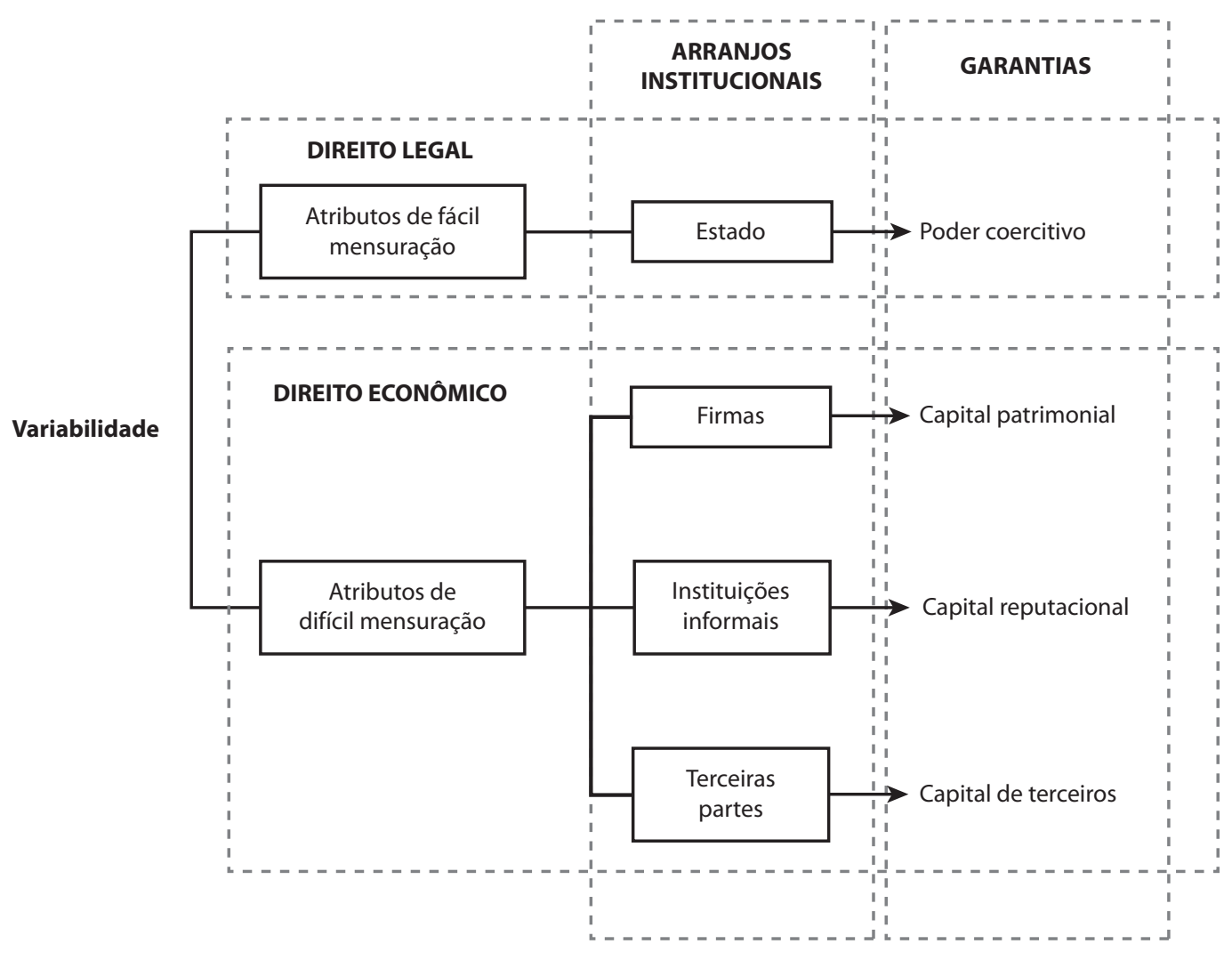


ineficiente alocação das garantias. Quando o agente responsável pela variabilidade do atributo não assume a responsabilidade em prover as garantias necessárias à transação, algum valor estará em domínio público, passível, portanto, de captura. Tem-se, assim, um terreno fértil para que assimetrias no poder de barganha ou assimetria de poder de mercado gerem ineficiências no processo de trocas, contribuindo para a ocorrência de falhas de coordenação. Posto isso, fica clara a importância da análise da cadeia de garantias da transação para a identificação de falhas potenciais de coordenação. Uma "cadeia de garantias" é exemplificada na Figura 1.

\section{Hipóteses de pesquisa}

A análise da "cadeia de garantias" do SAG da carne bovina em Mato Grosso do Sul tem como foco a transação produtor - indústria frigorífica, tendo como produto o animal (boi ou vaca) para abate. Busca-se identificar a relação do padrão das garantias e do padrão da transação com a percepção de risco dos pecuaristas relacionada ao não recebimento do pagamento pela venda dos animais para abate. Ainda, busca-se, também, investigar o papel das instituições formais (Judiciário) e das ações coletivas (associações de classe e organizações de produtores) como suporte à falta de garantias da transação.

Esta pesquisa parte de alguns pressupostos: i) a percepção de risco dos produtores rurais está relacionada à falta de garantias na transação de venda de animais para abate; ii) considerando-se a venda de animais para abate, a baixa ou média confiança dos produtores rurais na justiça está relacionada ao baixo delineamento dos direitos de propriedade e à baixa efetividade dos mecanismos judiciais para garantir a transação, o que, por sua vez, resulta em alta percepção de risco do produtor rural; iii) o desenvolvimento de ações coletivas por produtores rurais resulta em maior poder de barganha e garantias à transação, o que, por sua vez, representa menor percepção de risco de produtores rurais; iv) o histórico de conflito de produtores rurais com a indústria frigorífica resulta em alta percepção de risco da transação por parte de produtores.

Partindo desses pressupostos, esta pesquisa é conduzida com base em quatro principais hipóteses em relação à percepção de risco da transação:

i) Hipótese 1 (Papel das instituições formais): a percepção de risco da transação é minimizada quando o delineamento dos direitos de propriedade é claro e garantido pelas instituições formais (mecanismos judiciários) (BARZEL, 1982, 1997, 2001);

ii) Hipótese 2 (Papel das instituições informais): a percepção de risco da transação é minimizada na presença de ação coletiva dos agentes (instituições informais) (GRANDORI, 1995);

iii) Hipótese 3 (Padrão da transação): a percepção de risco da transação é minimizada quando o padrão da transação envolve maior frequência, maior tempo de relacionamento entre os agentes e maior proximidade entre as unidades de produção (frequência, reputação e especificidade locacional) (WILLIAMSON, 1985, 1996);

iv) Hipótese 4(Padrão do conflito): a percepção de risco da transação é potencializada na presença de históricos de conflitos anteriores ("path dependence") (NORTH, 1991).

\section{Metodologia}

Trata-se de uma pesquisa qualitativa - quantitativa. A pesquisa qualitativa é desenvolvida por meio de entrevistas semiestruturadas com lideranças do setor produtivo e da indústria frigorífica do estado de Mato Grosso do Sul. A abordagem quantitativa é desenvolvida com a aplicação de questionários estruturados para a avaliação do comportamento e da percepção de risco dos pecuaristas de Mato 
Grosso do Sul em relação à comercialização de gado para abate. A percepção de risco de não recebimento do valor da venda dos animais risco alto, médio ou baixo - é analisada com base em um conjunto de variáveis relacionadas ao perfil do produtor rural, ao padrão da transação e ao padrão das garantias envolvidas. Objetiva-se, também, entender o papel das instituições formais (mecanismos legais) e das ações coletivas (associações de produtores rurais) como suporte à falta de garantias da transação.

Como critério de escolha das variáveis para compor o modelo econométrico, adotou-se, primeiramente, as variáveis com fundamentação teórica para explicar o fenômeno da percepção de risco (falta de garantias). Posteriormente, procedeu-se a uma análise da matriz de correlação das variáveis de pesquisa com a percepção de risco da transação.

Os resultados baseiam-se na aplicação de 107 questionários a pecuaristas no estado de Mato Grosso do Sul durante o mês de março de 2010. A percepção de risco do pecuarista é avaliada a partir da pergunta: "Em relação à comercialização do gado com o frigorífico, qual o grau de risco de não receber pela venda do animal: alto, médio ou baixo?". Trata-se de uma amostra não probabilística, pois parte é caracterizada como uma amostra autogerada (52,34\% dos questionários aplicados) e parte como amostra aleatória $(47,66 \%)$, resultado do sorteio de nomes de pecuaristas que realizaram venda de animais para abate em janeiro e fevereiro de 2010 e constam do cadastro da Agência Estadual de Defesa Sanitária Animal e Vegetal (Iagro/MS). O cadastro disponibilizado pela Iagro contava com 324 pecuaristas.

As entrevistas foram realizadas com os próprios pecuaristas responsáveis pela comercialização do gado para abate, sendo eles os tomadores de decisão sobre o padrão da comercialização. Os questionários foram, preferencialmente, aplicados por telefone $(67,29 \%)$, havendo algumas entrevistas presenciais $(27,10 \%)$ e outras realizadas foram via e-mail $(5,61 \%)$.

Os dados são analisados em duas etapas por meio de regressões logísticas múltiplas.
Inicialmente, desenvolve-se uma regressão logit ordenada ("ordered logit") para a investigação dos fatores relacionados à percepção de risco da transação. Posteriormente, propõe-se um modelo probit bivariado recursivo ("recursive bivariate probit") para se investigar, de modo simultâneo, a influência direta de ações coletivas na percepção de risco da transação, dado que essa relação tem fundamentação teórica. A análise é realizada com apoio do pacote estatístico Stata10.

$\mathrm{Na}$ regressão logit ordenada, as variáveis independentes estão relacionadas: i) ao perfil do produtor rural (tradição na atividade; participação da pecuária na geração de renda no negócio rural; atividades de engorda na produção de animais para abate; uso de inseminação artificial como tecnologia de produção); ii) ao padrão do conflito (ocorrência de problemas de não recebimento do gado comercializado com o frigorífico; quantidade de vezes em que ocorreu falta de pagamento pelo gado vendido ao frigorífico; utilização de mecanismos judiciários em caso de não recebimento); iii) ao padrão de garantias e da transação (participação em associações de produtores; alta e média confiança na justiça, distância da indústria frigorífica, tempo de relacionamento com a indústria frigorífica, frequência da comercialização e prazo de pagamento "à vista").

No modelo probit bivariado recursivo estimam-se duas regressões simultâneas. Na primeira equação, tem-se a percepção de risco (variável dependente) relacionada com algumas variáveis do perfil do produtor rural, padrão do conflito e padrão de garantias e da transação, entre elas, as ações coletivas (participação em associações de classe/organizações de produtores). Na segunda equação, a participação em associações torna-se a variável dependente.

Assim, de modo simultâneo, investigam-se as variáveis explicativas para o fenômeno da percepção de risco da transação, dado que a participação em associações de classe (ações coletivas) tem forte influência na percepção de risco. Ademais, a adoção do probit bivariado recursivo decorre da necessidade de se evitarem erros na 
estimação, no caso de ambas as regressões serem dependentes. A ideia é que as duas decisões são inter-relacionadas e a estimativa separada geraria estimadores viesados. O modelo probit bivariado permite testar a independência dos resíduos das duas regressões e confirmar a necessidade de se desenvolverem análises simultâneas.

Como o modelo probit bivariado não permite a utilização de variável dependente ordenada, transformou-se a variável dependente " percepção de risco" em uma variável dicotômica, agrupando as percepções de alto e médio risco. Justifica-se o agrupamento da percepção "alta" com a "média", e não a "média" com a "baixa", pelo fato de que, quando da realização da pesquisa, se constatou uma mudança radical no padrão da transação que deve ter influenciado a escolha pela opção "média" em detrimento da percepção de risco "alta". A transação era tradicionalmente realizada por meio de venda a prazo (30 dias), do que decorria uma alta percepção de risco. Com a falência de várias indústrias frigoríficas na região pesquisada, iniciou-se uma campanha por venda à vista (na verdade, ainda com um prazo de dois a três dias úteis) o que, acredita-se, tenha fortemente influenciado os pecuaristas entrevistados a optar pela percepção "média" para o risco da transação no momento da aplicação do questionário.

\section{Padrão da transação e cadeia de garantias no SAG carne bovina}

A transação que é objeto de análise nesta pesquisa é a efetuada entre produtores rurais e empresas frigoríficas no denominado "mercado spot", que envolve a venda de gado para abate.

$\mathrm{O}$ animal para abate não é um produto unidimensional. Além do gênero (macho ou fêmea), do seu peso e idade, dimensões tradicionalmente reconhecidas pela indústria, um conjunto de outros atributos e subprodutos é transacionado inserido neste produto genericamente denominado "animal terminado para abate". Atributos de qualidade, sanidade e rastreabilidade são também negociadas no momento da venda. Além desses atributos, partes do animal, como o sangue, as vísceras, os ossos e o couro são, também, além da carne, produtos e subprodutos do processo de abate. Assim, o animal para abate é um exemplo clássico de um produto multidimensional.

O padrão de transação deste ativo multidimensional pressupõe o estabelecimento de um preço para cada $15 \mathrm{~kg}$ do animal (arroba), sendo este valor geralmente atrelado ao peso morto do animal. Este rendimento varia, principalmente, em função da raça do animal, das condições de alimentação, da idade e também da habilidade do funcionário da indústria frigorífica de fazer a limpeza (toalete) da carcaça. Assim, no mercado spot, o produtor é remunerado com base no peso final da carcaça (carne e ossos) do animal e do preço acordado entre as partes. Outros produtos, como vísceras, sangue e couro, constituem subprodutos do abate que não são pagos ao produtor. Em geral, existe muita incerteza sobre a aferição do rendimento de abate, não estando claro ao produtor, no momento da venda, qual será o montante final do valor a ser recebido pela comercialização.

Constata-se, assim, que o animal para abate apresenta um conjunto de margens - idade, peso, gênero, condições de sanidade, rastreabilidade, acabamento de gordura, vísceras, couro, entre outras - e que parte destas margens não é contratada no momento da comercialização do animal. Com isso, existe um conjunto de margens na transação que, ao não ser efetivamente contratado, cai em domínio público, tornando-se passível de captura pelos agentes econômicos; no caso, a indústria frigorífica. Abre-se, assim, espaço para conflitos na transação de diferentes ordens - discussão sobre rendimentos de carcaça, não remuneração de atributos de qualidade, descontos em função de não conformidade do animal, a não remuneração pelo couro etc. Em se tratando de mercado spot, o conflito mais aparente parece ser o não pagamento dos animais vendidos para as indústrias por falência das empresas.

De modo geral, a comercialização do gado terminado para abate é realizada por meio 
de venda direta ao frigorífico ou por meio de intermediários. Nas situações de venda direta ao frigorífico, o produtor entra em contato com funcionários da indústria para se informar sobre o preço praticado e negociar diretamente o volume de animais a ser abatido, o preço e o prazo. As empresas frigoríficas também efetuam a compra por meio de terceirizados comissionados. Em algumas situações, esses profissionais não só fazem a intermediação da compra do gado como acompanham o embarque e o abate dos animais.

Identificam-se três modalidades de intermediação:

i) O intermediário é um comprador representante do frigorífico, com relação de exclusividade com a empresa. A comissão é paga pela indústria;

ii) O intermediário é um profissional autônomo que representa diferentes indústrias. O produtor possui uma relação de confiança com este profissional que, além de informar os preços praticados no mercado, realiza a intermediação da compra e pode até acompanhar o abate dos animais. A comissão é paga tanto pelo produtor quanto pela indústria. Em média, o produtor paga $1 \mathrm{~kg}$ de carne/ cabeça comercializada;

iii) Intermediação com garantias: o intermediário é um profissional que efetivamente garante parte da transação estando essa garantia relacionada ao rendimento de carcaça e/ou à totalidade da transação (garantia de recebimento pelo animal comercializado). $\mathrm{Na}$ modalidade de garantia total da transação, têm-se a garantia sobre o rendimento de carcaça e a garantia de pagamento. Por se tratar de uma modalidade que implica assumir o risco total da transação, ela não é muito comum;

iv) "Marchand": o intermediário é um comerciante de carne. Ele compra os animais dos pecuaristas, abate numa planta frigorífica terceirizada e vende a carne no varejo. Em geral, o pagamento pelo serviço prestado pelo frigorífico é a entrega dos subprodutos de abate (e.g. sangue, vísceras e couro).

Os preços e os prazos de pagamento são estabelecidos pela indústria. Os preços acompanham as médias praticadas pelo mercado, sendo a escala de abate da indústria uma variável importante na variação do preço ofertado. Em geral, os prazos são "à vista" ou 30 dias. Os "preços à vista" são, na realidade, valores pagos com uma defasagem de três a cinco dias do abate e incorporam um deságio que varia de 3 a $5 \%$, a depender da negociação estabelecida entre as partes. Estabelecida a negociação, o animal é pesado e embarcado na propriedade rural. Para a efetivação da venda e do transporte dos animais, os produtores precisam emitir a Nota Fiscal do Produtor na Secretaria de Estado da Fazenda (Agenfa/Sefaz) e a Guia de Transporte Animal (GTA) na Agência Estadual de Defesa Animal e Vegetal (Iagro). O transporte dos animais é, em geral, realizado por transportadora própria da empresa frigorífica ou por empresas terceirizadas contratadas pelo frigorífico. O custo do frete é de responsabilidade da empresa frigorífica.

Mesmo sendo a venda negociada com pagamento à vista, o recebimento do valor devido ocorre somente após o abate dos animais na indústria com a avaliação do rendimento de abate e da condição de carcaça do animal. Uma vez realizado o abate, avalia-se o rendimento dos animais e a condição da carcaça para posterior emissão da Nota Promissória Rural (NPR).

A NPR é emitida em nome do produtor rural e entregue a ele como garantia do pagamento. A NPR apresenta um aval, sendo este, em geral, realizado pelo responsável pela sua emissão, na maioria das vezes um funcionário do setor comercial da empresa sem responsabilidade legal pelo negócio. Emitida a NPR e de acordo com o prazo estabelecido, a empresa efetua o pagamento na conta corrente bancária designada. Em caso de necessidade de adiantamento, o produtor poderá descontar a referida NPR em banco credenciado e, para tanto, incidirá um percentual de desconto. 
Observa-se que, da entrega dos animais na fazenda até o efetivo recebimento da NPR, não existem garantias formais para o recebimento dos valores devidos. Ademais, os produtores entregam os animais sem nem mesmo ter uma garantia do peso efetivo, visto que as pesagens realizadas no embarque na fazenda constituem apenas uma referência que será posteriormente validada nas balanças da indústria. Somente após o abate e a avaliação das carcaças é que o produtor terá informações precisas do rendimento alcançado pelos animais e do valor devido pela empresa frigorífica. É somente neste estágio do processo que ele recebe um documento, a NPR, que lhe qualifica como credor da empresa.

\section{Resultados e discussão}

O fenômeno da falta de garantias na transação produtor-indústria foi analisado com base em: i) perfil do produtor rural; ii) padrão do conflito e iii) padrão da transação e garantias. A análise descritiva dos dados é apresentada nos quadros de 1 a 3 .
Com base no Quadro 1 (perfil dos produtores), constata-se que mais de metade do grupo de pecuaristas apresenta alto grau de instrução, mais de 20 anos na atividade pecuária, renda fortemente dependente dessa atividade e com nível tecnológico intermediário (idade média de abate dos animais entre 20 e 36 meses, uso de suplementação nutricional na época da seca e de inseminação artificial como tecnologia para a reprodução dos animais).

Conforme pressupostos da pesquisa, a falta de garantias na transação é um fator determinante para a percepção de risco, sendo que, do total de entrevistados, mais da metade relatou problemas de não recebimento do pagamento pelos animais comercializados com os frigoríficos; desses, quase a metade relata que o problema ocorreu mais de uma vez e há menos de cinco anos (Quadro 2). É importante destacar que, entre os entrevistados que relataram problemas de recebimento, menos da metade recorreu à justiça como forma de rever seus direitos e, desses, menos de $20 \%$ responderam que os mecanismos judiciários foram efetivos para a solução do problema. De modo geral, $63 \%$ dos entrevistados afirmam

Quadro 1. Perfil dos produtores.

\begin{tabular}{|c|c|c|c|c|c|}
\hline & $\mathrm{Qt}$ & $\%$ & & $Q t$ & $\%$ \\
\hline \multicolumn{3}{|c|}{ Tempo na atividade } & \multicolumn{3}{|c|}{ Escolaridade } \\
\hline $1 \mathrm{a} 10$ anos & 11 & 10,28 & $1^{\text {o }}$ grau & 17 & 16,19 \\
\hline 11 a 20 anos & 26 & 24,30 & $2^{\mathrm{o}}$ grau & 15 & 14,29 \\
\hline 21 a 30 anos & 40 & 37,38 & 3o grau (ou mais) & 73 & 69,52 \\
\hline$>30$ anos & 30 & 28,04 & & & \\
\hline \multicolumn{3}{|c|}{ Tradição na atividade } & \multicolumn{3}{|c|}{ Abate / ano } \\
\hline $1^{a}$ geração & 22 & 20,56 & $<500$ & 35 & 33,98 \\
\hline $2^{\mathrm{a}}$ geração & 37 & 34,58 & 501 a 2000 & 46 & 44,68 \\
\hline $3^{\text {a }}$ geração & 22 & 20,56 & 2001 a 5000 & 14 & 13,59 \\
\hline $4^{\text {a }}$ geração (ou mais) & 26 & 24,30 & $>5000$ & 8 & 7,77 \\
\hline \multicolumn{3}{|c|}{$\%$ da renda / pecuária } & \multicolumn{3}{|c|}{ Tecnologia produção } \\
\hline Até $50 \%$ & 17 & 16,04 & Pasto & 48 & 45,28 \\
\hline $51 \%$ a $99 \%$ & 24 & 22,64 & Suplementação & 35 & 33,96 \\
\hline $100 \%$ & 65 & 61,32 & Confinamento & 22 & 20,75 \\
\hline \multicolumn{3}{|c|}{ Idade de Abate } & \multicolumn{3}{|c|}{ Inseminação Artificial } \\
\hline Até 20 meses & 1 & 0,94 & Sim & 53 & 50 \\
\hline 20 a 36 meses & 78 & 73,58 & Não & 53 & 50 \\
\hline$>36$ meses & 27 & 25,47 & & & \\
\hline
\end{tabular}


ter baixo grau de confiança na justiça. Entre as principais razões citadas para a baixa confiança na justiça, e em ordem decrescente de importância, estão: i) morosidade; ii) a atual legislação não prioriza o pagamento dos fornecedores de gado; iii) baixa efetividade dos resultados da justiça; iv) existência de sócios "laranjas" e v) custos advocatícios.

A participação em associações de classe/ organização de produtores é relatada por mais de $80 \%$ dos entrevistados, sendo o maior índice de aprovação creditado à participação em alianças mercadológicas. Em segundo lugar de importância, têm-se as representações sindicais (sindicatos rurais, federações estaduais e confederação nacional). Independente do tipo de associação/organização dos produtores, mais da metade $(51,11 \%)$ dos entrevistados tem baixo grau de confiança nas associações de classe como forma de prover garantias ao pagamento dos animais abatidos pelos frigoríficos.

O levantamento de dados da pesquisa coincidiu com uma importante mudança no padrão da transação entre produtor rural e indústria frigorífica. Até então, o prazo de pagamento era tradicionalmente de 30 dias após o abate e a avaliação do rendimento do animal. Com a falência de diversas empresas em 2009, iniciou-se uma campanha por venda "à vista". Assim, os frigoríficos, para garantirem a entrega dos animais, passaram a pagar com dois a três dias úteis após o abate, o que aparentemente representou uma melhoria na percepção de risco da transação. Devido a essa mudança no padrão da transação, mais de $80 \%$ dos entrevistados relatam como prazo a "venda à vista", o que não seria razoável esperar poucos meses antes da aplicação da pesquisa, quando o padrão da transação era a venda a prazo (30 dias) com a possibilidade de desconto de NPR.

Conforme indicado no Quadro 3, a comercialização do gado é, em grande maioria, realizada por meio de compradores do próprio frigorífico $(46,73 \%)$ e por intermediários $(41,12 \%)$, estando esses últimos relacionados com a redução da assimetria de informação (preços, escala,

Quadro 2. Padrão do conflito/garantias.

\begin{tabular}{|c|c|c|c|c|c|}
\hline & Qt & $\%$ & & $Q \mathbf{t}$ & $\%$ \\
\hline \multicolumn{3}{|c|}{ Percepção do Risco } & \multicolumn{3}{|c|}{ Problemas de recebimento } \\
\hline Alta & 29 & 27,10 & Sim & 64 & 59,81 \\
\hline Média & 40 & 37,38 & Não & 43 & 40,19 \\
\hline Baixa & 38 & 35,51 & & & \\
\hline \multicolumn{3}{|c|}{$\mathrm{N}^{\mathrm{o}}$ vezes / não recebimento } & \multicolumn{3}{|c|}{ Último não recebimento } \\
\hline $1 \mathrm{vez}$ & 35 & 54,69 & $<5$ anos & 31 & 48,44 \\
\hline 2 vezes & 11 & 17,19 & 5 a 10 anos & 14 & 21,88 \\
\hline 3 vezes & 12 & 18,75 & $>10$ anos & 19 & 29,69 \\
\hline$>3$ vezes & 6 & 9,38 & & & \\
\hline \multicolumn{3}{|c|}{ Entrou na justiça? } & \multicolumn{3}{|c|}{ Se entrou na justiça, resolveu? } \\
\hline Sim & 30 & 46,88 & Sim & 5 & 15,63 \\
\hline Não & 34 & 53,13 & Não & 27 & 84,38 \\
\hline \multicolumn{3}{|c|}{ Participa de associações? } & \multicolumn{3}{|c|}{ Grau de confiança na justiça } \\
\hline Sim & 90 & 84,11 & Alto & 12 & 11,21 \\
\hline \multirow[t]{2}{*}{ Não } & 17 & 15,89 & Médio & 27 & 25,23 \\
\hline & & & Baixo & 68 & 63,55 \\
\hline \multicolumn{3}{|c|}{ Grau de importância da associação? } & & & \\
\hline Alta & 29 & 32,22 & & & \\
\hline Média & 15 & 16,67 & & & \\
\hline Baixa & 46 & 51,11 & & & \\
\hline
\end{tabular}


garantia de rendimento) e relações de confiança. Em termos de frequência da transação, quase $80 \%$ dos entrevistados relatam comercializar mais de quatro vezes/ano, sendo esta decisão, com base nas respostas dos entrevistados, predominantemente relacionada à necessidade de gerenciamento de risco, a aspectos financeiros (liquidez) e a aspectos comerciais (melhores preços).

\subsection{Evidências econométricas}

A percepção de risco dos produtores em relação à venda de gado para abate (percepção alta, média ou baixa) é relacionada ao perfil do produtor rural, ao padrão da transação e das garantias. O Quadro 4 apresenta as variáveis adotadas nos modelos econométricos, a relação delas com as hipóteses de pesquisa e os sinais esperados.

Quadro 3. Padrão da transação/garantias.

\begin{tabular}{|c|c|c|c|c|c|}
\hline & Qt & $\%$ & & Qt & $\%$ \\
\hline \multicolumn{3}{|c|}{ Com quem comercializa } & \multicolumn{3}{|c|}{ Frequência da transação } \\
\hline Proprietário & 3 & 2,80 & 1 a 2 vezes/ano & 6 & 5,61 \\
\hline Comprador do frigorífico & 50 & 46,73 & 3 a 4 vezes/ano & 16 & 14,95 \\
\hline Intermediário & 44 & 41,12 & $>4$ vezes/ano & 85 & 79,44 \\
\hline Associação de produtores & 9 & 8,41 & & & \\
\hline \multicolumn{3}{|c|}{ Forma de pagamento } & \multicolumn{3}{|c|}{ Tempo médio de relacionamento } \\
\hline Antecipado & 5 & 4,67 & $<5$ anos & 31 & 29,81 \\
\hline "à vista" & 89 & 83,18 & 5 a 10 anos & 48 & 46,15 \\
\hline Prazo (30 dias) & 13 & 12,15 & $>10$ anos & 25 & 24,04 \\
\hline \multicolumn{6}{|c|}{ Distância média do frigorífico } \\
\hline até $300 \mathrm{Km}$ & 82 & 78,10 & & & \\
\hline$>300 \mathrm{Km}$ & 23 & 21,90 & & & \\
\hline
\end{tabular}

Quadro 4. Variáveis do modelo e as hipóteses de pesquisa relacionadas.

\begin{tabular}{|c|c|c|c|}
\hline Hipóteses gerais & Descrição da variável & Tipo de variável & Sinal \\
\hline \multirow{4}{*}{ Variáveis de controle } & Tradição na atividade (terceira geração $=1$ ) & Dummy & + \\
\hline & Participação \% da atividade pecuária nos negócios rurais & Contínua & + \\
\hline & Produção dos animais em regime de "engorda" & Dummy & + \\
\hline & Tecnologia de produção para uso de inseminação artificial & Dummy & + \\
\hline \multirow{2}{*}{$\mathrm{H} 1$} & Alto grau de confiança na justiça & Dummy & - \\
\hline & Médio grau de confiança na justiça & Dummy & + \\
\hline $\mathrm{H} 2$ & Participação em associações/organizações de produtores & Dummy & - \\
\hline \multirow{4}{*}{$\mathrm{H} 3$} & $\begin{array}{l}\text { Tempo de relacionamento (em anos) com os frigoríficos com que } \\
\text { atualmente comercializa (maior valor em caso de mais de uma resposta) }\end{array}$ & Contínua & - \\
\hline & $\begin{array}{l}\text { Distância da fazenda (em } \mathrm{km} \text { ) dos frigoríficos com que atualmente comer- } \\
\text { cializa (maior valor em caso de mais de uma resposta) }\end{array}$ & Contínua & + \\
\hline & Alta frequência de vendas ( $>4$ vendas/ano) & Dummy & + \\
\hline & Prazo "a vista" para recebimento das vendas (três dias úteis) & Dummy & - \\
\hline \multirow{4}{*}{$\mathrm{H} 4$} & Percepção de risco da transação (alto/médio/baixo) & Dummy & \\
\hline & $\begin{array}{l}\text { Ocorrência de problemas de não recebimento do gado } \\
\text { comercializado com o frigorífico }\end{array}$ & Dummy & + \\
\hline & Número de vezes em que ocorreu problema de não recebimento & Discreta & + \\
\hline & Utilização de mecanismos judiciários em caso de não recebimento & Dummy & + \\
\hline
\end{tabular}




\section{a) Etapa 1: Modelo logit ordenado ("ordered logit")}

A Tabela 1 apresenta os resultados do modelo logit ordenado. Os dados são apresentados de forma incremental. No modelo (A), tem-se o resultado da regressão considerando-se somente as variáveis de controle. Nos modelos seguintes (modelos B a D), são agregadas à análise grupos de variáveis relacionadas a: i) padrão do conflito; ii) padrão de garantias e iii) padrão da transação.

Tabela 1. Modelo Logit Ordenado.

\begin{tabular}{|c|c|c|c|c|}
\hline \multirow{3}{*}{$\begin{array}{c}\text { Variável dependente } \\
\text { Método: } \\
\end{array}$} & \multicolumn{4}{|c|}{$\begin{array}{c}\text { Percepção de Risco } \\
(0=\text { baixa; } 1 \text { = média; } 2 \text { = alta })\end{array}$} \\
\hline & \multicolumn{4}{|c|}{ Logit ordenado } \\
\hline & A & B & $\mathrm{C}$ & D \\
\hline $\mathrm{N}^{\circ}$ observações & 106 & 106 & 106 & 103 \\
\hline Percepção de risco & Coef. & Coef. & Coef. & Coef. \\
\hline \multirow{2}{*}{$3^{\text {a }}$ geração } & 1,3846 & 1,4218 & 1,4334 & 1,395 \\
\hline & $(0,4721)^{* * *}$ & $(0,5249)^{* * *}$ & $(0,5433)^{* * *}$ & $(0,5532)^{* *}$ \\
\hline \multirow{2}{*}{ Participação pecuária } & $-1,7564$ & $-1,3581$ & $-1,3229$ & $-1,218$ \\
\hline & $(0,7949)^{* *}$ & $(0,7986)^{*}$ & $(0,8322)$ & $(0,8688)$ \\
\hline \multirow{2}{*}{ Atividade de engorda dos animais } & 1,3051 & 1,6333 & 1,4651 & 1,546 \\
\hline & $(0,8119)$ & $(0,8316)^{* *}$ & $(0,8755)^{*}$ & $(0,8988)^{*}$ \\
\hline \multirow{2}{*}{ Usar inseminação artificial } & $-0,5468$ & $-0,5225$ & $-0,7493$ & $-0,689$ \\
\hline & $(0.3873)$ & $(0,4116)$ & $(0,4344)^{*}$ & $(0,4452)$ \\
\hline \multirow{2}{*}{ Ter histórico de problema de não recebimento } & & 0,9202 & 0,6506 & 0,639 \\
\hline & & $(0,5539)^{*}$ & $(0,5891)$ & $(0,5946)$ \\
\hline \multirow{2}{*}{ Quantidade de eventos de problemas não recebimento } & & 0,0768 & 0,060 & 0,020 \\
\hline & & $(0,1894)$ & $(0,1943)$ & $(0,1969)$ \\
\hline \multirow{2}{*}{ Ter tido problema e recorrido à justiça } & & 0,7265 & 0,9178 & 1,101 \\
\hline & & $(0,5518)$ & $(0,5898)$ & $(0,6077)^{*}$ \\
\hline \multirow{2}{*}{ Ter confiança alta na justiça } & & & $-0,3503$ & $-0,374$ \\
\hline & & & $(0,6995)$ & $(0,7120)$ \\
\hline \multirow{2}{*}{ Ter confiança média na justiça } & & & 0,8851 & 0,924 \\
\hline & & & $(0,4832)^{*}$ & $(0,5101)^{*}$ \\
\hline \multirow{2}{*}{ Participar de associações de classe } & & & 1,7185 & 1,631 \\
\hline & & & $(0,6503)^{* * *}$ & $(0,6726)^{* *}$ \\
\hline \multirow{2}{*}{ Tempo de relacionamento com frigoríficos } & & & & 0,0011 \\
\hline & & & & $(0,0291)$ \\
\hline \multirow{2}{*}{ Distância dos frigoríficos } & & & & 0,00005 \\
\hline & & & & $(0,0015)$ \\
\hline \multirow{2}{*}{ Frequência alta de venda } & & & & 0,0154 \\
\hline & & & & $(0,5225)$ \\
\hline \multirow{2}{*}{ Prazo “à vista” } & & & & $-0,0153$ \\
\hline & & & & $(0,6470)$ \\
\hline Log likelihood & $-105,61521$ & $-98,536567$ & $-92,971242$ & $-90,684758$ \\
\hline LR chi2 & 19,90 & 34,06 & 45,19 & 43,12 \\
\hline Prob > chi2 & 0,0005 & 0,0000 & 0,0000 & 0,0001 \\
\hline Pseudo R2 & 0,0861 & 0,1474 & 0,1955 & 0,1921 \\
\hline
\end{tabular}


Com base na Tabela 1, entende-se que a regressão $\mathrm{D}$ apresenta grau adequado de ajuste $(\chi 2=43.12$ e $\mathrm{p}<0.0001)$, e alguns parâmetros individuais apresentam significância a $5 \%$ e $10 \%$. A regressão não apresenta multicolinearidade entre as variáveis explicativas ( $\mathrm{VIF}<10)$ e também não apresenta heterocedasticidade nos resíduos (teste Breusch-Pagan/ Cook-Weisberg). Ainda, no modelo $\mathrm{D}$, as variáveis testadas estão relacionadas a todas as hipóteses de pesquisa, o que não ocorre nos modelos anteriores. Optou-se por adotar o modelo D e considerar os regressores como exógenos.

Com base nos resultados do modelo logit ordenado, pode-se afirmar que as hipóteses relacionadas com o papel das instituições formais (H1b) e o papel das instituições informais (H2) foram validadas com grau de significância de 10\% e 5\%, respectivamente. A hipótese relacionada com o argumento de "path dependence" (padrão do conflito - H4c) também é validado a $10 \%$ de significância. As variáveis relacionadas ao padrão da transação não apresentam significância a 5\% ou $10 \%$. Supõe-se que tal fato decorre da baixa especificidade do atributo transacionado (carne commodity) e da baixa reputação da indústria frigorífica. Assim, a alta frequência da transação não estaria relacionada à construção da reputação, mas, sim, à necessidade de o pecuarista gerenciar o risco, uma vez que a comercialização é feita de modo parcelado. Da mesma forma, o tempo de relacionamento com a indústria não permite a construção da confiança entre os agentes, sendo o histórico de conflito um importante fator para o comportamento "path dependence" do pecuarista.

\section{b) Etapa 2: Modelo probit bivariado recursivo ("recursive bivariate probit")}

Há interesse em se investigar a influência direta da participação em ações coletivas na percepção de risco para o que o método probit bivariado recursivo mostre-se adequado. Assim, de modo simultâneo, investigam-se as variáveis explicativas para o fenômeno da percepção de risco da transação e da participação em associações de classe (ações coletivas). Os resultados das regressões bivariadas são apresentados na Tabela 2.
A análise da Tabela 2 aponta que as regressões estão ajustadas $\left(\chi^{2}=84.17, \mathrm{p}<0.0000\right)$ e as variáveis dependentes ("percepção de risco" e "participação em associações") são perfeitamente relacionadas, porém, de modo inverso $\left(\mathrm{rho}^{5}=-1\right)$. $\mathrm{O}$ teste LR para rho $=0\left(\chi^{2}=2.84113, \mathrm{p}<0.0919\right)$ sugere que os resíduos são correlacionados com significância de $10 \%$. A correlação dos resíduos confirma a necessidade do método bivariado para a estimação das regressões.

Considerando-se os resultados apresentados para a regressão em que a participação em associação de classe é a variável dependente (Tabela 2), as variáveis "ter alta confiança na justiça" e "ter confiança média na justiça" apresentam, respectivamente, $1 \%$ e $10 \%$ de significância. É razoável supor que os produtores que confiam, mesmo que não totalmente, nos mecanismos judiciários têm maior probabilidade de participar de associações de classe, podendo ser essa uma ação complementar para a garantia de seus direitos. Ter histórico de não recebimento dos animais vendidos para abate tem significância de 5\% para explicar a probabilidade de fazer parte de uma associação de produtores/classe. $\mathrm{O}$ volume de abate - número médio de animais abatidos/ ano pelo produtor - apresenta significância estatística a $10 \%$. Assim, maior escala de produção (maior volume de animais para abate) explicaria uma maior probabilidade de ser membro de uma associação. Essa lógica não é trivial, pois se espera que pequenos produtores desenvolvam ações coletivas, e não os grandes produtores. Pode-se, no entanto, sugerir que pecuaristas de pequeno porte (baixa escala de produção) não entendam como relevante a participação em associações de produtores/classe por identificarem-nas como representações lideradas por grandes produtores que buscam defender interesses próprios ${ }^{6}$.

\footnotetext{
5 "rho" é um parâmetro de correlação das duas regressões do modelo probit bivariado recursivo e mede o grau de correlação dos resíduos das equações, assumindo o valor " 0 " (zero) no caso de ausência de correlação e " 1 " (um) para correlação perfeita.

6 Esse argumento está de acordo com Lazzarini (2007) que, ao analisar redes globais no segmento de aviação, identificou que a decisão por fazer parte de uma rede
} 
Tabela 2. Modelo Probit Bivariado Recursivo.

\begin{tabular}{|c|c|c|}
\hline Variável dependente & $\begin{array}{l}\text { Percepção de Risco } \\
(0=\text { baixa; } 1 \text { = alta })\end{array}$ & $\begin{array}{l}\text { Participação em Associação } \\
\text { de Classe ( } 0=\text { não; } 1=\text { sim })\end{array}$ \\
\hline Método: & \multicolumn{2}{|c|}{ Probit Bivariado recursivo } \\
\hline $\mathrm{N}^{\circ}$ observações & \multicolumn{2}{|c|}{100} \\
\hline Log likelihood & \multicolumn{2}{|c|}{$-81,47433$} \\
\hline Wald chi2 & \multicolumn{2}{|c|}{84,17} \\
\hline \multirow[t]{2}{*}{ Prob > chi2 } & \multicolumn{2}{|c|}{0.0000} \\
\hline & Coef. & Coef. \\
\hline \multirow{2}{*}{ 3aㅡ Geração } & 0,790 & 0,608 \\
\hline & $(0,3547)^{* *}$ & $(0,4403)$ \\
\hline \multirow{2}{*}{ Abate } & & 0,0003 \\
\hline & & $(0,0002)^{*}$ \\
\hline \multirow{2}{*}{ Atividade de engorda dos animais } & 8,138 & 0,158 \\
\hline & $(1,45 e+07)$ & $(0,7139)$ \\
\hline \multirow{2}{*}{ Ter histórico de problema de não recebimento } & & 0,686 \\
\hline & & $(0,3483)^{* *}$ \\
\hline \multirow{2}{*}{ Ter tido problema e recorrido à justiça } & 0,493 & 0,4939 \\
\hline & $(0,3231)$ & $(0,5354)$ \\
\hline \multirow{2}{*}{ Ter confiança alta na justiça } & & $-1,614$ \\
\hline & & $(0,4898)^{* * *}$ \\
\hline \multirow{2}{*}{ Ter confiança média na justiça } & 0,878 & $-0,6731$ \\
\hline & $(0,3491)^{* *}$ & $(0,3943)^{*}$ \\
\hline \multirow{2}{*}{ Participar de associações de classe } & 2,345 & \\
\hline & $(0,3376)^{* * *}$ & \\
\hline \multirow{2}{*}{ Tempo de relacionamento com frigorífico } & $-0,001$ & \\
\hline & $(0,019)$ & \\
\hline \multirow{2}{*}{ Distância do frigorífico } & 0,0003 & \\
\hline & $(0,010)$ & \\
\hline \multirow{2}{*}{ Prazo “à vista" } & 0,669 & \\
\hline & $(0,4199)$ & \\
\hline \multirow{2}{*}{ Cons } & $-2,356$ & 0,5431 \\
\hline & $(0,6301)$ & $(0,3475)$ \\
\hline /athrho & \multicolumn{2}{|c|}{$-13,41342$} \\
\hline Rho & \multicolumn{2}{|c|}{-1} \\
\hline chi2(1) & \multicolumn{2}{|c|}{2,84113} \\
\hline Prob > chi2 & \multicolumn{2}{|c|}{0,0919} \\
\hline \multicolumn{3}{|c|}{ Likelihood-ratio test of rho $=0$} \\
\hline
\end{tabular}

Considerando-se a primeira regressão, em que a percepção de risco é a variável dependente, "participar de associações de classe" é significativa a 1\%. "Ter tradição na atividade pecuária” (terceira geração) e "ter confiança média na justiça"

global de aviação deve considerar o tamanho da rede e a capacidade de operação do entrante. Caso contrário, não há benefício em ser membro da rede. apresentam significância a 5\%. Ressalta-se, ainda, que a correlação perfeitamente negativa entre as variáveis dependentes ("percepção de risco" e "participação de associações de classe") poderia ser interpretada com uma opção que o produtor tem entre participar de uma associação de classe (ação coletiva) ou ter percepção de risco alta. Assim, ações coletivas seriam como um 
contraponto para a alta percepção de risco ou falta de garantias da transação.

Com isso, pode-se afirmar que as hipóteses relacionadas com o papel das instituições formais (H1b) e o papel das instituições informais (H2) foram validadas com grau de significância de $5 \%$ e $1 \%$, respectivamente. As hipóteses relacionadas com o argumento de "path dependence" e com o padrão da transação não apresentaram validação estatística.

\section{c) Validação geral das hipóteses de pesquisa}

Considerando-se os dois modelos econométricos, observa-se que as hipóteses 1 e 2 são validadas em ambos os modelos, e a hipótese 3 não é validada em nenhum deles. A hipótese 3 é validada somente no modelo logit ordenado.

O papel das instituições formais (hipótese H1b) foi validado em ambos os modelos testados. Para os produtores entrevistados, a média confiança na justiça implica aumento na probabilidade de se ter alta percepção de risco. Isto confirma a deficiência dos mecanismos judiciários em prover garantias à transação.

O papel das instituições informais (hipótese H2) é também validado em ambos os modelos testados. Omodelobivariado permite, ainda, inferir que a decisão de fazer parte de uma associação de classe pode ser entendida como uma alternativa para a alta percepção de risco da transação, uma vez que as regressões bivariadas são perfeitamente correlacionadas, porém, de forma negativa. Poder-se-ia argumentar que a opção de se tornar membro de uma associação de classe teria um viés de seleção, uma vez que aqueles produtores que de alguma forma possuem uma percepção de risco mais aguçada tenderiam a buscar a proteção por meio de uma coordenação horizontal. É importante destacar que a variável que trata da participação em associações não representa um juízo de valor dessa instituição. Inclusive, questões relacionadas à importância dessa associação para a garantia de recebimento dos valores devidos pela indústria não apresentaram correlação significativa com a percepção de risco. Assim, independente da importância dessa associação para o problema analisado (venda de gado para o frigorífico), a decisão por desenvolver uma ação coletiva está associada a alguma percepção de risco na atividade produtiva.

As hipóteses relacionadas ao padrão da transação (hipótese 3) não foram validadas por nenhum dos modelos testados nesta pesquisa, demonstrando que os padrões de transação analisados não explicam a percepção de risco dos pecuaristas. A baixa especificidade do produto, a associação da frequência da transação à gestão de risco e os problemas de reputação da indústria frigorífica (que não permitem que uma relação de confiança seja estabelecida ao longo do tempo entre os agentes e que nem mesmo a venda "a vista" seja associada ao baixo risco) explicariam a não validação dessas hipóteses.

O histórico do conflito e, por conseguinte, os mecanismos de "path dependence" (hipótese H4c), são validados no modelo logit ordenado.

\section{Conclusão}

Esta pesquisa considera os aspectos institucionais das falhas organizacionais, sendo a análise desenvolvida para o SAG da carne bovina em Mato Grosso do Sul (MS). As falhas organizacionais dizem respeito à falta de garantias na transação entre pecuaristas e a indústria frigorífica e que estão especificamente relacionadas ao não recebimento pelo gado vendido ao frigorífico. Investiga-se o papel das instituições formais e informais para a solução de conflitos nesse SAG, além da avaliação da importância do padrão da transação e do histórico de conflito na percepção de risco dos produtores. Em linhas gerais, conclui-se que: i) os mecanismos judiciários não proveem as garantias necessárias para que a transação ocorra de modo eficiente; ii) as instituições informais (associação de produtores/ classe) representam uma alternativa para fazer frente à alta percepção de risco da transação; iii) o padrão da transação (distância do frigorífico, tempo de relacionamento entre os agentes, frequência da transação e prazo de pagamento) não explica a percepção de risco dos 
produtores e iv) o histórico do conflito contribui para a percepção de risco dos produtores rurais.

Como contribuição para a literatura, entende-se que essa pesquisa, ao partir da lógica da "ineficiência" dos arranjos institucionais e da regularidade das falhas, instiga outros pesquisadores a explorar facetas da Nova Economia Institucional que não são tradicionalmente abordadas. Esta pesquisa propõe como elemento para a análise das falhas organizacionais a ideia de "cadeia de garantias". Sugere-se que a análise institucional deve contemplar, além da estrutura de garantias oferecidas pelos agentes (contratos e hierarquia), também as garantias oferecidas pelo ambiente institucional formal e informal, sendo o padrão dessas garantias parte relevante do estudo das falhas organizacionais. Assim, a "cadeia de garantias" é uma ferramenta para a compreensão das falhas em sistemas complexos. A cada atributo transacionado, uma cadeia de garantias está associada, e é a partir de sua análise que é possível identificar a possibilidade da ocorrência das falhas. A ideia central está em estudar a criação de valor pela sua vertente inversa, a dissipação de valor e, para isso, considerar a estrutura de garantias relacionadas à transação, à variabilidade do atributo, ao padrão dos direitos transacionados e dos arranjos institucionais adotados para sua coordenação. Entende-se esse modelo como um novo olhar para o estudo das falhas organizacionais.

Ademais, nesta pesquisa é possível identificar como um dos determinantes das falhas de coordenação no SAG da carne bovina e da consequente alta percepção de risco dos produtores, a ineficiência dos mecanismos judiciários (instituição formal) em garantir o direito de o produtor receber pelo gado vendido à indústria frigorífica. Em se tratando de relações de mercado, em que o risco é uma variável intrínseca da negociação comercial, entende-se que o papel do Estado é de fortalecer os mecanismos legais para que os conflitos sejam dirimidos a contento.

Assim, a título de políticas públicas sugere-se: (i) reavaliação da classificação de créditos na Lei de Recuperação Judicial das empresas de abate e processamento de carne bovina; (ii) identificação de mecanismos que contribuam para maior agilidade das decisões judiciais de modo a não tornar a decisão por recuperação judicial uma "indústria" que facilite o comportamento oportunístico dos agentes e (iii) revisão de normas e critérios para a concessão de licenças de operação para novas empresas no setor de abate e processamento de carne bovina.

Entre algumas sugestões de estratégia privada têm-se: (i) identificação de mecanismos privados que configurem maior segurança à transação, tais como (ia) a venda eletrônica de gado para abate com pagamento antecipado de parte do valor transacionado, (ib) realização de campanhas de esclarecimento na classe produtora para a necessidade da venda à vista do gado e (ic) maior formalização do processo de negociação; (ii) fortalecimento das ações coletivas dos produtores rurais, seja em torno de instituições representativas da classe ou participação em cooperativas e alianças mercadológicas.

Cabe ressaltar algumas limitações da pesquisa. Em termos empíricos, especificamente em relação à amostra, é fato que a mesma não confere aleatoriedade aos dados e que não contempla um universo representativo dos pecuaristas de Mato Grosso do Sul - não se obteve uma representação regional e temporal na amostra utilizada. A não existência de um banco de dados confiável e disponível para pesquisas abrangentes no setor de carne bovina no estado de Mato Grosso do Sul e, senão, em outros estados do País, além das restrições de ordem financeira e temporal justificam a abordagem adotada.

Ainda, cumpre destacar que é exatamente no fortalecimento das ações coletivas que reside um dos aspectos centrais desta pesquisa, tangenciando-se, simultaneamente, um de seus maiores desafios. Ao se ressaltar a importância das ações coletivas, outras dimensões das falhas passam a emergir, quais sejam, as restrições de ordem cognitiva, comportamental e cultural. A dificuldade de organização do setor poderia ser atribuída, em tese, a aspectos comportamentais e culturais da classe produtora, notadamente aos 
pecuaristas voltados à produção de gado de corte. Esse ponto, apesar de crucial, não foi abordado na presente pesquisa, representando, portanto, um bom caminho para investigações futuras.

Da mesma forma, outras dimensões das falhas - tais como as relações de confiança e os aspectos relacionados à estrutura de mercado (natureza estrutural) - também não foram explorados nesta pesquisa. Essas "ausências", antes de representarem uma limitação da pesquisa, incentivam a construção de um arcabouço ainda mais geral das falhas organizacionais. Fica, assim, lançado o desafio: a construção de uma teoria das falhas que permita analisar de modo integrativo o fenômeno das falhas de coordenação em sistemas agroindustriais complexos.

\section{Referências bibliográficas}

BARZEL, Y. Measurement cost and the organization of markets. The Journal of Law and Economics, v. XXV. p. 2748, April, 1982.

BARZEL, Y. Economic analysis of property right. 2nd ed. Cambridge: University Press, 1997.

BARZEL, Y. A theory of organizations to supersede the theory of the firm. Working paper - Department of Economics, Washington, 2001. Disponível em: <http// www. econ. washington.edu/people/detail.asp?uid =yoramb $>$. Acesso em: 22 set. 2007.

BARZEL, Y. Organizational forms and measurements costs. In: Annual Conference of the International Society for the New Institutional EconomicS, 6., 2002, Cambridge, Massachusetts. Disponível em: $<$ http// www. isnie.org > Acesso em: 20 jan. 2007.

DEMSETZ, H. Toward a theory of property rights. The American Economic Journal, v.57, n. 2, p. 347-359, May 1967.

EUCLIDES FILHO, K. Rastreamento e Certificação. Agroanalysis, v. 24, n. 4, p. E15-E16, abr. 2004.

FARINA, E. M. M. Q e NUNES, R. Desempenho do agronegócio no comércio exterior e governança nos sistemas agroindustriais das carnes de suinos e das carnes bovinas. In: XXXI ENCONTRO NACIONAL DE ECONOMIA, 31., 2003, Porto Seguro - Bahia. Disponível em: < http:// www.econpapers.repec.org/paper/anpen2003/e27. htm >. Acesso em: 25 out. 2011.

FERREIRA, G. C. e BARCELLOS, M. D. Vantagens $e$ desvantagens das alianças estratégicas: uma análise sob a ótica dos agentes da cadeia produtiva da carne bovina. Organizações Rurais \& Agroindustriais, v. 8, n.1, p. 117-130, 2006

GRANDORI, A. e SODA, G. Inter-firm networks: antecedents, mechanisms and forms. Organizational studies, v.16, n. 2, p. 183-214, 1995.

GREENE, W. H. Econometric Analysis. 5th ed. New Jersey: Prentice Hall, 2003.

INDEPENDÊNCIA S. A - Plano de Recuperação Judicial Relatório KPMG: apresentação sobre análise preliminar e desempenho financeiro recente. Disponível em $<$ www.independência.com.br> Acesso em 30/06/2009.

JANK, M. S. Competitividade do agribusiness brasileiro: discussão teórica e evidências no sistema carnes. São Paulo, 1996. Tese (Doutorado em Administração). Programa de Pós Graduação em Administração, Departamento de Administração, Faculdade de Economia, Administração e Contabilidade da Universidade de São Paulo.

MADDALA, G. S. Limited Dependent and Qualitative Variables in Econometrics. New York: Cambridge University Press, 1983.

MALAFAiA, G. C. et al. Atitudes de coordenação de produtores rurais na cadeia da carne bovina: o caso Cite 120. In: $30^{\circ}$ Encontro EnANPAD, 30., 2006, Salvador. Disponível em: <http://www.aproccima.com.br > Acesso em: 25 out. 2011.

NORTH, D. C. Institutions. The journal of economic perspectives, v.5, n.1, p. 97-112, 1991.

PEROSA, J. M. Y. Papel da coordenação em alianças de mercado: análise de experiência no SAG carne bovina. In II Workshop Brasileiro de Gestão de Sistemas Agroalimentares, 2., 1999, Ribeirão Preto. Disponível em: < http://www.fearp.usp.br/ egna/arquivo/6.pdf> Acesso em: 25 out. 2011.

PIGATTO, G. et al. Alianças Mercadológicas: A busca da Coordenação na Cadeia de Gado de Corte Brasileira. In II Workshop Brasileiro de Gestão de Sistemas Agroalimentares, 2., 1999, Ribeirão Preto. Anais... Ribeirão Preto:USP, p. 200-209. 1999.

ROCHA, J. C. M. C. et al. Experiências com alianças verticais na coordenação da Cadeia Produtiva da Carne Bovina no Brasil. In: III Congresso Internacional de Economia e Gestão de Negócios AgroalimentareS, 3., 2001, Ribeirão Preto. Disponível em: $<$ http://www.fearp.usp.br/egna/ resumos/Rocha.pdf > Acesso em: 25 out. 2011.

SIFFERT FILHO, N. e FAVERET FILHO, P. O sistema agroindustrial de carnes: competitividade e estruturas de governança.Disponívelem: $<$ http//www.bndes.gov.br $>$. Acesso em: 25 out. 2011. 
SINDICATO RURAL DE CAMPO GRANDE. Um histórico de quebras, inadimplências e longas recuperações judiciais. Informe Agropecuário, Campo Grande, p. 6-7, mar. 2009.

WIAZOWSKI, B. A. e LIRIO, V. S. Cadeia produtiva de bovinos de corte: uma análise sistêmica de sua competitividade. In: IV Worhshop brasileiro de gestão de sistemas agroindustriais, 4, 2003. CD-ROM.

WILLIAMSON, O. E. The Economic Institutions of Capitalism: Firms, Markets, Relational Contracts. New York: The Free Press, 1985.
WILLIAMSON, O. E. The Mechanisms of Governance. New York: Oxford University Press, 1996.

ZYLBERSZTAJN, D. Papel dos contratos na coordenação agro-industrial: um olhar além dos mercados. Revista de Economia e Sociologia Rural, v.43, n.3, p. 385-420, 2005.

ZYLBERSZTAJN, D. e MACHADO FILHO, C. A. P. Competitiveness of meat agribusiness chain in Brazil and Latin America. Working paper n. 00/010, set. 2000. Disponível em: <http// www.ead.fea.usp.br/wpapers/ index.htm > Acesso em: 25 out. 2011. 